\title{
Manfaat Asuransi Usahatani Padi dalam Menanggulangi Risiko Kerusakan Akibat Hama Penyakit (Studi Kasus pada Subak Sangeh, Desa Sangeh, Kecamatan Abiansemal, Kabupaten Badung, Provinsi Bali)
}

\author{
NI KADEK MARITA DEWI, KETUT BUDI SUSRUSA, IDA AYU LISTIA DEWI \\ Program Studi Agribisnis, Fakultas Pertanian, Universitas Udayana \\ Jl. PB Sudirman Denpasar 80232 Bali \\ Email: maritadewi7@gmail.com \\ kbsusrusa@gmail.com
}

\begin{abstract}
Benefits of Insurance of Rice Insurance in Eradication of Damage Risk Because of Diseases (Case Study in Sangeh Subak, Sangeh Village, Abiansemal District, Regency of Badung, Bali Province)
\end{abstract}

The rat attack that occurred in July 2017 resulted in 8.96 ha of land in Subak Sangeh

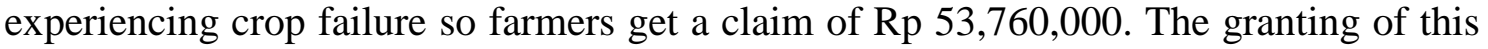
claim is intended to enable farmers to cover losses due to damage to the previous planting season and to have the capital of farming in the next planting season. Based on that it is interesting to do research on the benefits of rice farm insurance in tackling the risk of damage caused by pest disease in Subak Sangeh, as well as farmers response to the program.Farmers' responses were analyzed qualitatively with attitude approach based on percentage of average score obtained through structured interviews using questionnaires. While the benefits of rice farm insurance are analyzed quantitatively based on the ratio of claims fund to production cost.The result of comparison of claim fund with production cost of Subak Sangeh in one planting season is $121,54 \%$ or more than $100 \%$, meaning rice farm insurance has benefit in tackling damage caused by pest, farmers response is positive, seen from the attitude of farmers in general agreed to the socialization and implementation of the program.

Keywords: Rice Farm Insurance, Benefits, Production Cost, Response, Attitude.

\section{Pendahuluan}

\subsection{Latar Belakang}

Sektor pertanian saat ini merupakan sektor yang identik dengan ketidakpastian (uncertainty), kebergantungan pada musim berpengaruh negatif terhadap hasil pertanian. Hal ini terlihat dengan semakin meningkatnya harga-harga produk pertanian sebagai efek turunnya produksi akibat perubahan cuaca (Kementrian Pertanian, 2017). Kondisi kenaikan harga tersebut tidak berpengaruh banyak terhadap pendapatan petani (Bramantia, 2011). Pemerintah telah mengeluarkan berbagai kebijakan untuk membantu petani meminimalisir dampak negatif dari kondisi ini, namun dianggap belum efektif sehingga diperlukan strategi yang lebih sistematis misalnya sistem asuransi pertanian (Nurmanaf et al. (2007) dalam Satwikani, 2018). Sejalan dengan upaya tersebut, maka pemerintah meluncurkan program Asuransi Usahatani Padi (AUTP) yang 
ditindaklanjuti dengan penerbitan Permentan Nomor 40 Tahun 2015 tentang fasilitasi asuransi pertanian. Pemerintah bekerjasama dengan PT. Asuransi Jasa Indonesia (PT. Jasindo) sebagai perusahaan penanggung risiko dan membantu melaksanakan program AUTP di seluruh wilayah Indonesia (Pasaribu, et.al., 2010).

Program AUTP mulai dilaksanakan pada Oktober 2015 dan Provinsi Bali sebagai salah satu sentra produksi padi turut menjadi peserta (Provinsi Bali, 2017). Menurut data Jasindo dan Dinas Pertanian Provinsi Bali(2017) luas areal peserta AUTP pada MT Oktober 2016 - Maret 2017 adalah 647,11 ha diikuti oleh 4 (empat) kabupaten dan kota yaitu Denpasar, Tabanan, Klungkung dan Badung, sedangkan pada MT April September 2017 adalah 608,64 ha diikuti oleh 7 (tujuh) kabupaten dan kota yaitu Denpasar, Tabanan, Buleleng, Jembrana, Klungkung, Badung dan Bangli. Luas klaim terbesar terdapat di Kabupaten Tabanan, yaitu 516,61 ha, termasuk proporsi luas klaim dengan luas areal yang diasuransikan terbesar terdapat di Kabupaten Tabanan, diikuti dengan Kabupaten Bangli, dan Kabupaten Badung (Jasindo, 2017).

Penurunan luas areal peserta terbesar terletak di Kabupaten Badung yaitu 15,10 ha, adapun proporsi luas klaim dengan luas areal yang diasuransikan terbesar di Kabupaten Badung terletak di Subak Sangeh yang mencapai 8,55\% dari total luas klaim di Kabupaten Badung yaitu, 11,70\% pada MT April 2017 - September 2017 (Pemkab Badung, 2017).

Subak Sangeh mengasuransikan seluruh lahan usahatani padinya seluas 200 ha dengan total premi yang dibayarkan Rp 7.200.000,- yang dibantu oleh dana APBD Kabupaten Badung. Serangan tikus yang terjadi pada Juli 2017 mengakibatkan 8,96 ha lahan di Subak Sangeh mengalami gagal panen sehingga petani mendapatkan klaim Rp 53.760.000,-. Pemberian klaim ini bertujuan agar petani dapat menutupi kerugianakibatkerusakan pada musim tanam sebelumnya dan memiliki modal berusahatani di musim tanam berikutnya.

\subsection{Rumusan Masalah}

Berdasarkan uraian di atas, dapat dirumuskan permasalahan sebagai berikut.

1. Bagimana manfaat Asuransi Usaha Tani Padi dalam menanggulangi risiko kerusakan akibat hama penyakit bagi Subak Sangeh, Desa Sangeh, Kecamatan Abiansemal, Kabupaten Badung, Provinsi Bali?

2. Bagaimana respon petani terhadap program AUTP di Subak Sangeh, Desa Sangeh, Kecamatan Abiansemal, Kabupaten Badung, Provinsi Bali?

\subsection{Tujuan Penelitian}

Berdasarkan rumusan masalah di atas, maka penelitian ini bertujuan untuk mengetahui hal-hal berikut ini.

1. Besarnya manfaat Asuransi Usaha Tani Padi dalam menanggulangi risiko kerusakan akibat hama penyakit bagi Subak Sangeh, Desa Sangeh, Kecamatan Abiansemal, Kabupaten Badung, Provinsi Bali.

2. Respon petani terhadap program AUTP di Subak Sangeh, Desa Sangeh, Kecamatan Abiansemal, Kabupaten Badung, Provinsi Bali.

\section{Metode Penelitian}

\subsection{Lokasi dan Waktu Penelitian}

Penelitian dilakukan pada bulan Februari sampai dengan Mei 2018. Lokasi penelitian dilakukan di Subak Sangeh, Desa Sangeh, Kecamatan Abiansemal, 
KabupatenBadung, Provinsi Bali. Penentuan lokasi penelitian tersebut dilakukan secara sengaja (purposive), didasarkan atas pertimbangan sebagai berikut.

1. Subak Sangeh yang terletak di Desa Sangeh, Kecamatan Abiansemal, Kabupaten Badung telah dihadapkan pada tingginya serangan hama tikus dan merupakan daerah endemik tungro yang berpotensi menyebabkan gagal panen (BPP Kecamatan Abiansemal, 2017), dan

2. Subak Sangeh memiliki proporsi luas klaim dengan luas areal yang diasuransikan terbesar diantara dua subak lainnya yang mencapai 8,55\% dari total luas klaim dengan luas areal yang diasuransikan di Kabupaten Badung sebesar 11,70\% pada MT April - September 2017.

\subsection{Jenis dan Sumber Data}

Berdasarkan sumbernya, data yang dikumpulkan terdiri dari data primer dan sekunder. Data primer diperoleh langsung dari petani penerima dana klaim AUTP menggunakan kuesioner, sedangkan wawancara mendalam dengan Pangliman dan PPL dilakukan untuk mendapatkan gambaran pelaksanaan AUTP. Data sekunder diperoleh melalui data pendukung yang dimiliki oleh instansi terkait seperti data penyebab kerusakan, nilai premi, luas dan besarnya klaim AUTP di Subak Sangeh maupun di Provinsi Bali.

Berdasarkan jenisnya, data yang dikumpulkanterdiridari data kualitatifberupa data karakteristikumum, dansikap petanisebagairesponpetaniterhadap program AUTP, dan data kuantitatifmeliputi data jumlahpetani yang memperoleh dana klaim,biayaproduksi, luasdanbesarnyaklaim yang diterimapetani di SubakSangeh.

\subsection{Metode Pengumpulan Data}

Adapun metode pengumpulan data yang akan dilakukan dalam penelitian ini adalah sebagai berikut.

1. Wawancara, pengumpulan data dilakukan dengan dua jenis wawancara, yaitu wawancara terstruktur dengan petani menggunakan kuesioner, serta wawancara mendalam dengan Pangliman dan PPL Desa Sangeh mengenai gambaran umum dan pelaksanaan AUTP di Subak Sangeh.

2. Observasi, yaitu mengamati langsung aktivitas petani di lokasi penelitian, dan konsistensi petani menjawab kuesioner.

3. Dokumentasi dengan mencatat, merekam, dan mengambil gambar atau informasi pada berbagai dokumen yang dimiliki oleh instansi terkait, seperti PT. Jasindo, BPP Kecamatan Abiansemal, dan Dinas Pertanian Provinsi Bali maupun dokumen yang dimiliki oleh Subak Sangeh.

\subsection{Populasi dan Sampel}

Jumlah populasi petani yang telah mendapat dana klaim AUTP pada MT April 2017 - MT September 2017 di Subak Sangeh adalah sebanyak 42 orang. Sehubungan dengan jumlah populasi tersebut adalah kurang dari 100, maka jumlah sampel dalam penelitian ini adalah seluruh jumlah populasi, yaitu sebanyak 42 orang.

\subsection{Instrumen Penelitian}

Penelitianinimenggunakaninstrumenpenelitianberupakuesionersehinggasetiap

item harusdiujivaliditasdanreliabilitasnya (Wati, 2017). Ujivaliditasdanreliabilitasdalampenelitianinidilakukanpadaaspeksikap. 


\subsection{Konsep dan Variabel Penelitian}

Adapunkonsepdalam penelitian ini meliputi manfaat AUTP dan respon petani terhadap program AUTP, denganvariabeloperasional meliputi perbandingan dana klaim AUTP dengan biaya produksi yang diukur menggunakan skala rasio dan sikap yang diukur dengan skala ordinal.

\subsection{Analisis Data}

Metodeanalisis data dalampenilitianinidiantaranyametodeanalisis data kualitatifyang digunakanuntukmenggambarkankarakteristikrespondendanresponterkaitsikappetanibe rdasarkanpadasosialisasidanpelaksanaan AUTP.Pengukuransikappetanidengan total program pernyataanberbentukkalimatpositifdannegatif. PenilaiansikapmenggunakanskalaLikert dengan lima kategorijawabanyaituSangatTidakSetuju (STS), TidakSetuju (TS), RaguRagu (R), Setuju (S) danSangatSetuju(SS).Pernyataanpositifdiberikanskor 1 untukjawabanSangatTidakSetuju (STS), skor 2 TidakSetuju (TS), skor 3 Ragu-Ragu (R), skor 4 Setuju (S), danskor 5 SangatSetuju (SS). Sedangkanuntukpernyataannegatifpemberianskornyaadalahkebalikandariskorpernyata anpositif.Berdasarkanskor yang diperolehkemudiandijumlahkan, dirata-ratakan dan dikalikan $100 \%$. Sehingga diperoleh persentase sikap petani.

Metode analisis data kuantitaif yang dilakukan terdiri dari pengumpulan danpengolahan data, yang meliputi analisis manfaat AUTP dalam menanggulangi kerusakan akibat hama penyakit. Manfaat AUTP dapat terlihat dengan membandingkan antara dana klaim AUTP dengan biaya produksi usahatani padi dalam 1 kali musim tanam, atau dapat menggunakan pendekatan rumus yang telah dimodifikasi sebagai berikut (Arikunto (2002) dalam Satwikani, 2018).

$$
\text { Persentase }=\begin{array}{lllllllll} 
& K & -K & D & K 1 & A & (K / n u) & \\
\hline K & -K & B & P & & U & n a & \mu & (K / n u)
\end{array} \times 100 \% .
$$

Mengacupadatujuanpemberianklaimsebagai

modal penanamankembalidimanaklaimditentukansebesarbiayaproduksisehinggadaripersentas e yang diperolehdapatdikategorikanmenjadi: persentase $<\quad 100 \%$ makaklaimdinyatakanbelumdapatmenanggulangirisikokerusakanakibathamapenyakit, sedangkanpersentase $\geq \quad 100 \%$ makaklaimdinyatakandapatmenanggulangirisikokerusakanakibathamapenyakit.

\section{Hasil dan Pembahasan}

\subsection{Karakteristik Responden}

Karakteristikumumresponden yang dikumpulkanmeliputiumur, jeniskelamin, pendidikan, pekerjaanpokok, pekerjaansampingan, status kepemilikanlahandanluasgarapan. Berdasarkan hasil penelitian yang telah dilakukan, sebagianbesar umur petani penerima klaim AUTP $(73,80 \%)$ adalah respondenberumurtidak produktifnamun masihbekerjasebagaipetanidenganalasantidakmemilikipekerjaan lain maupuntidakmemilikigenerasipenerusuntukmelanjutkankegiatanusahatani. Kontribusi terbesar dalam kegiatan usahatani padi di Subak Sangeh adalah responden berjenis kelamin laki-laki, jadi penerima klaim AUTP mayoritas adalah laki-laki (92,85\%). 
Mayoritas pendidikan petani penerima klaim AUTP tergolong masih rendah, yaitu sebagian besar tamatan SD (76,19\%). Sedangkan pekerjaan pokokpenerima dana klaim AUTP mayoritas sebagai petani $(85,72 \%)$ Hal inididugakarenalatarbelakangpendidikanpetani_yang cenderungrendahdankurangnyaketerampilanuntukmencaripenghasilantambahan.ratarata respondendenganpekerjaanpokoksebagaipetanimemilikipekerjaansampinganmenjadip eternak $(85,72 \%)$ danrespondendenganpekerjaanpokokselainpetanibekerjasampingansebagaipetani (14,28\%). Hal inimenunjukkanbahwamayoritaspenerima dana klaim AUTP memilikipekerjaansampingansebagaipeternak.

Mayoritaspetani $(92,85 \%)$ mengusahakanlahanmilik orang lain dansisanya $(7,15 \%)$ mengusahakanlahanmiliksendiri. Hal inimenunjukkanbahwamayoritas petani penerima klaim AUTP di SubakSangehmasihmengusahakanlahanmilik orang lain. Apabiladikelompokkanberdasarkankategori BPS tersebut, makamayoritaspetani $(97,62 \%) \quad$ adalahpetaniguremdan $\quad(2,38 \%) \quad$ bukanpetanigurem. Tidakditemukanpetanimenggaraplahandiatassatu ha. Luas lahangarapandari 42 respondendiikutsertakandalam program AUTP pada MT April 2017 - September 2017 danmemenuhiketentuanluaslahangarapan yang diperbolehkanmenjadipesertayaitumaksimumduaha.

\subsection{Manfaat Asuransi Usahatani Padi (AUTP)}

Manfaat AUTP dilihatdariperbandingan dana klaim AUTP denganbiayaproduksiusahatanipadi. Biayaproduksiusahatanipadiadalahbiaya yang dikeluarkansebelumpanen per luasgarapanselamasatumusimtanamyaitudaribulan April sampaiJuli 2017 meliputipembeliansaranaproduksidanbiayatenagakerjaluarkeluargauntukpengolahanla handanpenanaman.Berikutdisajikanpenggunaan input dan rata - rata biayaproduksi yang dikeluarkanpetani di SubakSangeh per rata - rata luaslahangarapan 0,23 ha sesuai Tabel 1.

\section{Tabel 1.}

Perbandingan Dana Klaim AUTP denganBiayaProduksi di SubakSangeh, DesaSangeh, KecamatanAbiansemalKabupatenBadung 


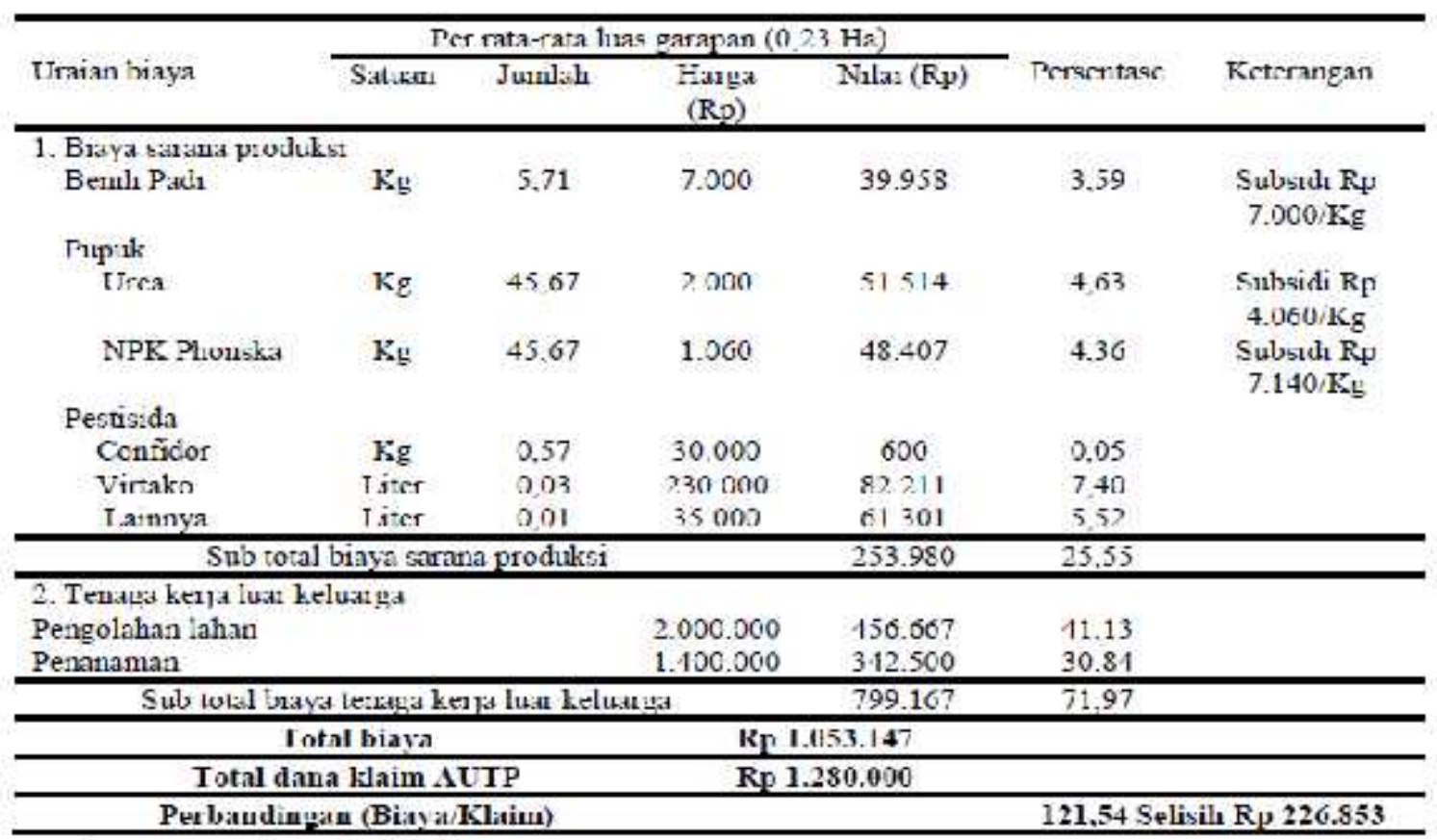

Sumber Data Primer (Diolah) 2018.

Kontribusibiayaterbesaradalahbiayatenagakerjaluarkeluargayaitu

$71,97 \%$.

Biayatenagakerjaluarkeluarga

terbesaruntukpengolahanlahandidugakarenahargasewatraktor

meningkatseiringmeningkatnyahargaminyakdanupahsopirtraktor.

yang

terbatasnyatenagasopirtraktormenjadikendalasaatpengolahanlahandilakukanserempak.

Respondenlebihbanyakmenggunakantenagaupahanuntukkegiatanpenanamankarenapet aniberusialanjut.Rata - rata biayaproduksi yang dikeluarkan petani per rata - rata luas lahan garapan 0,23 ha adalahsebesar Rp1.053.147dibandingkandengandanaklaimA U TP yaitusebesarRp1.280.000makadapatdisimpulkanbahwadana klaim AUTP dapatmemberikanmanfaatdalammenanggulangi kerugian akibat kerusakan yang disebabkan oleh serangan hama penyakit yang besarnya adalah 121,54\% dimanaterdapatkelebihan dana sebesarRp 226.853, sehinggarata - rata biayaproduksiyang dikeluarkan petani dapatditutupidengan dana klaimAUTP karenaadanya bantuan subsididaripemerintahpusatdanKabupatenBadungmeliputisubsidibenihdanpupuk.

Berdasarkanhasilpenelitiandisimpulkan dana klaim AUTP mampumenutupibiayaproduksiusahataniyaknisampaitahapanpenanamandanpemelihar aan. Hal initelahsesuaidengantujuanpemberianklaimyaitumenjaminketersediaan modal untukpenanamankembali di musimtanam berikutnyasehinggakegiatanusahatanidapat tetapberlangsung.

\subsection{Respon Petani terhadap Program AUTP}

Respon petani terhadap program AUTP dilihat dari sikap responden terhadap sosialisasi dan pelaksanaan program AUTP yang dinilai dengan pengajuan pernyataan yang berbentuk kalimat positif dan negatif.Pengukuran sikap petani dengan pengajuan 20 pernyataan yang berbentuk kalimat positif dan negatif. Penilaian sikap menggunakan skala Likert dengan lima kategori jawaban yaitu Sangat Tidak Setuju (STS), Tidak Setuju (TS), Ragu-Ragu (R), Setuju (S), dan Sangat Setuju (SS). 
Berdasarkanhasilpenelitian, dapatdisimpulkansecarakeseluruhansikappetanisetujuterhadap program AUTP yang meliputisosialisasidanpelaksanaanprogram AUTP.

a. Sikap petani terhadap sosialisasi program AUTP

Sikap petani secara umum setuju terhadap sosialisasi program AUTP. Hal ini dapat diartikan bahwa sosialisasi telah berlangsung dengan baik ditinjau dari kemudahan memahami penjelasan yang diberikan, kesulitan berinteraksi dengan petugas dan manfaat sosialisasi untuk menambah wawasanpetani.

b. Sikap petani terhadap pelaksanaan programAUTP

Sikappetanisecara umum setuju terhadappelaksanaan program AUTP. Hal iniberkaitandenganresponpetaniterhadap program AUTP ditinjaudari proses pendaftaran, pengajuan, pembayaranklaimdanpelayanan program yang telahterlaksanadenganbaik. Secara lebih rinci dijelaskan sebagai berikut.

1. Sikap petani terhadap pendaftaran programAUTP.

Sikappetaniterhadappendaftaran program

AUTP ditinjaudarikesulitanpetanimemenuhisyaratpendaftaran, kesesuaianpremidenganmanfaat yang diperolehpetani, penerimaanpetaniterhadapsistempembagianpremi yang ditentukanpemerintah, penerimaanpetaniterhadapjenis OPT yang dijaminasuransitelahmencakupsemuajenis OPT yang menyerangpadi. Secaraumumsikappetanisetujuterhadappendaftaran program AUTP.

2. Sikap petani terhadap pengajuan klaim AUTP

Sikappetanisecaraumumsangat setujuterhadappengajuanklaim

AUTP ditinjaudarikesulitanmengajukanlaporankerusakandanpenerimaanpetaniterhadapjumla hklaim AUTP per hektar.

3. Sikap petani terhadap pembayaran klaim AUTP

Sikappetaniterhadappembayaranklaim AUTP prosespembayaranklaimdankesesuaianjumlahklaim diterimapetanidenganhasilverifikasiJasindo.

Secaraumumsikappetanisangatsetujumengenai pembayaranklaim AUTP.

4. Sikap petani terhadap pelayanan program AUTP

Sikappetaniterhadap program AUTP ditinjaudari rasa amanberusahatani, ketidakpuasanpetanidenganpelayanan, tercapainyatujuan AUTP ditentukandariperanpetugasasuransi, POPT/PHP dan PPL dalammemberipelayanan, ketidaksesuaianpelayananpetugasasuransidenganprosedur AUTP, petugasasuransilambatdalammenanggapilaporankerusakan, kemampuandanpengetahuanpetugasasuransimenghitungluaskerusakandengantepat, POPT/PHP terampildanhandalmenanganikerusakan, kesulitanmenghubungi POPT/PHP dankelayakan program untukdilanjutkan secara umum setuju.

\section{Simpulan dan Saran}

\subsection{Simpulan}

Berdasarkanpadahasilanalisis yang diperoleh, makadisimpulkanhal halsebagaiberikut. 
1. Manfaat AUTP dalam menanggulangi risiko kerusakan akibat hama penyakit terlihat dari perbandingan dana klaim AUTP dengan biaya produksi yaitu sebesar $121,54 \%$ atau lebih besar dari $100 \%$, artinya AUTP mampu menanggulangi kerugian akibat kerusakan yang disebabkan oleh hama penyakit dan faktor lain, besarnya dana klaim AUTP lebih besar dari rata - rata biaya produksi yang dikeluarkan oleh petani, sehingga tujuan AUTP untuk menjamin ketersediaan modal berusahatani pada musim tanam berikutnya dapat dibuktikan.

2. Respon petani tergolong positif terhadap program AUTP dilihat dari sikap petani terhadap sosialisasi dan pelaksanaanprogram.

\subsection{Saran}

Berdasarkanpadakesimpulan yang diperoleh, dapatdisarankanhal - halsebagaiberikut.

1. Program AUTP dapat dikembangkan di Subak Sangeh mengingat manfaat dana klaim yang diperoleh petani, dan program AUTP perlu diterapkan pada subak dengan tingkat kegagalan panen tinggi akibat serangan OPT dan potensi kegagalan panenlainnya khususnya di Kabupaten Badung Provinsi Bali.

2. Respon positif petani dilihat dari sikap petani terhadap sosialisasi dan pelaksanaan program AUTP tidak terlepas dari koordinasi Dinas Pertanian, PT. Jasindo, PPL dan perangkat subak lainnya yang sudah terjalin dengan baik sehingga perlu dipertahankan untuk pelaksanaan AUTPselanjutnya.

\section{Ucapan Terima Kasih}

Penelitian ini tidak akan terlaksana dengan baik tanpa adanya bantuan moral maupun material dari berbagai pihak. Sehingga pada kesempatan ini penulis memberikan ucapan terima kasih kepada seluruh pihak yang telah membantu dalam pelaksanaan penelitian hingga karya ilmiah ini dapat dipublikasikan di e-jurnal. 


\section{DAFTAR PUSTAKA}

Anonim.2010.Profil Desa Sangeh. www.badungkab.go.id. Dikutip pada 28 Januari 2018.

Anonim.2016.Tinjauan Pustaka Tentang Perkembangan Hama dan Penyakit. https://repository.uma.ac.id/118210004_file5. Dikutip pada 11 Pebruari 2018.

Anonim.2017.Pendahuluan.etd.repository.ugm.ac.id/downloadfile/7649/potongan/S1 -2014-299097-introduction.pdf. Dikutip pada 17 Januari 2018.

Anonim.2017.Jasindo Agri. www.jasindo.co.id/product/ritel/agri. Dikutip pada 17 Januari 2018.

Anonim. 2017. Kementrian Pertanian "Pedoman AUTP Tahun 2017”. http://psp.pertanian.go.id/assets/file/2017/Pedoman\%20AUTP\%202017.pdf. Dikutip 20 April 2018.

Anonim.2012. "Definisi Subak". www.baliprov.go.id. Dikutip 28 April 2018.

Bramantia, A.2011."Tinjauan Yuridis Asuransi Pertanian untuk Usahatani Padi pada Kasus Gagal Panen” (Skripsi).Jakarta:Universitas Indonesia.

Pasaribu, S.M, dkk.2010.Pengembangan Asuransi Usahatani Padi untuk Menanggulangi Risiko Keuntungan 75\% Akibat Banjir, Kekeringan dan Hama Penyakit. pse.litbang.pertanian.go.id/ind/pdffiles/MAKPROP_SHP.pdf. Dikutip pada 17 Januari 2018.

Satwikani, Arista. 2018. "Efektivitas Penggunaan Dana Klaim AUTP pada Subak Sengempel, Desa Bongkasa, Kecamatan Abiansemal, Kabupaten Badung" (Skripsi). Denpasar:Universitas Udayana.

Wati, Endang D. 2017. "Praktik Asuransi Usahatani Padi pada PT. AsuransiJasa Indonesia dalam Perspektif Masalah (Studi pada Petani Padi di Kecamatan Galur Kabupaten Kulon Progo)" (Skripsi). Yogyakarta:Universitas Islam NegeriSunan Kalijaga. 